\title{
Enhancement of Carrimycin Production Via Traditional Mutagenesis with Metabolic Engineering in Streptomyces Spiramyceticus 54IA
}

\section{Kemeng Li}

NHC Key Laboratory of Biotechnology of Antibiotics, Institute of Medicinal Biotechnology, Chinese Academy of Medical Sciences and Peking Union Medical College

Jianlu Dai

NHC Key Laboratory of Biotechnology of Antibiotics, Institute of Medicinal Biotechnology, Chinese Academy of Medical Sciences and Peking Union Medical College

\section{Juanjuan Liu}

NHC Key Laboratory of Biotechnology of Antibiotics, Institute of Medicinal Biotechnology, Chinese Academy of Medical Sciences and Peking Union Medical College

\section{Tianyi Hao}

NHC Key Laboratory of Biotechnology of Antibiotics, Institute of Medicinal Biotechnology, Chinese Academy of Medical Sciences and Peking Union Medical College

Weiqing He ( $\nabla$ heweiqing@imb.pumc.edu.cn )

NHC Key Laboratory of Biotechnology of Antibiotics, Institute of Medicinal Biotechnology, Chinese Academy of Medical Sciences and Peking Union Medical College

\section{Research Article}

Keywords: carrimycin, Streptomyces spiramyceticus 54IA, positive regulator, reporter gene

Posted Date: January 14th, 2022

DOI: https://doi.org/10.21203/rs.3.rs-1204059/v1

License: (c) (1) This work is licensed under a Creative Commons Attribution 4.0 International License. Read Full License 


\section{Abstract}

Background: Carrimycin is a new approved class I antibiotic in China. The novel carrimycin producing strain, Streptomyces spiramyceticus 54IA, was constructed by CRISPR-Cas9 editing system without insertion of antibiotics resistant gene. The problem of low yield limits this strain in large scale fermentation. In this study, the carrimycin production was significantly improved by strain mutagenesis coupled metabolic engineering.

Results: The $s s p D$ gene is responsible for degradation of triacylglycerol to provide precursors of the polyketide biosynthesis. The extra $s s p D$ gene controlled by the promoters of $p k s$ and $b s m 42$ genes could moderately enhance carrimycin production. The Bsm42 was identified to play a pathway-specific positive regulator for carrimycin biosynthesis. Due to production of carrimycin significantly enhanced by bsm42 overexpression, the two different length promoters of bsm42 individually ligated with two reporter genes were used to monitor bsm 42 expression for screening the higher carrimycin production mutants treated by plasma and ultraviolet. $47 \%$ of the 608 selected mutants had higher fermentation titer than the starting strain. The shorter promoter of bsm42 displayed more appropriate for selection of the carrimycin production improved mutants. The F2R-15 mutant had highest titer $(1010 \pm 30 \mu \mathrm{g} / \mathrm{mL})$, which was about 9 times higher than that of 54IA strain. Comparative analysis of transcriptome profiles of F2R-15 mutant and 54IA strains found 158 differential expression genes with more than 2 fold-changes. The upregulated genes were associated with macrolide precursor biosynthesis, macrolide-inactivation, antibiotics transporter, oxidative phosphorylation; while the most down-regulated genes were referring to the primary metabolites synthetic genes and biosynthetic genes of other secondary metabolites.

Conclusion: These results suggested that manipulation of the positive regulatory gene bsm 42 and traditional mutagenesis coupled with reporter-guided mutant selection method facilitated selection of carrimycin high-yielding mutants.

\section{Background}

Carrimycin, also known as bitespiramycin and shengjimycin, is a new, hybrid macrolide antibiotic approved by the China National Medical Products Administration in 2019. It is produced by recombinant Streptomyces spiramyceticus, which harbors a 4"-O-isovaleryltransferase gene (ist) from Streptomyces thermotolerans [1, 2]. Carrimycin mainly consisted of isovalerylspiramycins I, II, III and contained trace amount of other 4"-O-acylspiramycin components [3]. Compared to spiramycin, carrimycin has a longer half-life, higher potency, and greater tissue penetration [4,5]; it shows potent inhibition to the $\mathrm{G}^{+}$ pathogens, and recently was identified as an antiviral agent against a broad-spectrum of human coronaviruses, including the SARS-Cov-2 virus [6].

The carrimycin engineering strain, Streptomyces spiramyceticus WSJ-195 [7], was resistant to apramycin, thiostreptomycin and kanamycin, and it is difficult to perform directed genetic manipulation for this strain using the existing Streptomyces plasmids. So, a novel carrimycin-producing strain (Streptomyces 
spiramyceticus 54IA) without resistant genes insertion into the genome was constructed by using CRISPR-Cas9 editing system [8]. The titer of carrimycin was improved through the ribosome engineering, but it was far from the requirement in the scale-up fermentation. Many efforts have been made to improve the production of carrimycin in Streptomyces spiramyceticus WSJ-195 in recent years, including traditional random mutagenesis [9, 10], medium optimization [11], exogenous feeding strategies [12, 13], fermentation process control [14], and genetic engineering [15]. Among these approaches, traditional mutagenesis is a powerful and easily operated method for strain improvement in Streptomyces, especially for microbes with less understanding of genomic information and metabolic mechanisms. Although the isovalerylspiramycins I (one component of carrimycin) high-producing strains have been developed with the composite mutagenesis of Plasma and UV [16], it is definitely laborious and timeconsuming to improve carrimycin production by just relying on random mutagenesis and ordinary screen methods. Thus, traditional mutagenesis should combine with rational metabolic engineering strategies to shorten the process of strain breeding.

Metabolic engineering strategies have been widely used in the improvement of secondary metabolites in microbes, especially for the production of antibiotics. Currently, the improved production of antibiotics through metabolic engineering mainly focuses on investigation of regulatory genes [17], improvement of precursor supply [18, 19], and comparative metabolomics profiling analysis [20, 21]. Among those strategies, enhanced precursor supply has been indicated to be a direct way to increase the accumulation of desired natural products. For example, the increased supply of propionyl-CoA carboxylase along with the addition of propionate was found to be an effective way to increase the concentration of intracellular methylmalonyl-CoA for rapamycin biosynthesis in S. hygroscopicus [22]. Spiramycin's structural backbone is a polyketide, putative platenolide I including ethylmalonyl-CoA, methylmalonyl-CoA and methoxymalonyl-CoA, which depends on polyketides synthase (PKS) and malonyl-CoA for its biochemical composition [23]. Wang et al [24] applied multi-omics to reveal that intracellular triacylglycerols (TAGs) pool as an intracellular carbon source for polyketide biosynthesis during stationary phase, and the mobilization of cellular TAGs enables carbon flux to be redirected to polyketide biosynthesis. They devised a new dynamic degradation of TAG (ddTAG) strategy that increases polyketide titers and applied ddTAG in four Streptomyces species to increase yields of actinorhodin (Act), jadomycin B, oxytetracycline and avermectin B1a. The sco6196 is the key gene involved in degradation of TAG in S. coelicolor. Given that accumulation of a TAG pool is widespread in actinomycetes [25]. The strategy of TAG appropriately degradation can be also widely used for improvement of polyketide antibiotics biosynthesis.

The positive regulatory genes of spiramycin biosynthesis, srm22 and srm40, also were identified in this gene cluster. Srm40 is a pathway-specific activator in spiramycin biosynthesis, and Srm22 is required for srm40 expression [26]. The bsm23 and bsm42 genes in Streptomyces spiramyceticus, homologous with srm22 and srm40, also play the positive regulatory genes involved in spiramycin biosynthesis [27]. The Bsm42 plays the role in the activation of spiramycin biosynthesis, and its overexpression can improve the yield of spiramycin. However, we discovered that Bsm23 inhibited spiramycin production at high expression level although it was a necessary regulatory gene for spiramycin biosynthesis. The expression 
level of the transcriptional activators can play as an indicator for high production of target metabolite. A double reporter-guided mutant selection method has been developed to facilitate selection of clavulanic acid high-yield mutants [28].

Carrimycin is a new potent drug for anti-infection and had antiviral activity. We constructed a new resistant marker-free strain Streptomyces spiramyceticus 54IA by CRISPR-Cas9 editing system. But the carrimycin production of 54IA is far lower than that of the WSJ-195 strain. In this study, the carrimycin production was improved by increasing expression of $s s p D$, homologous to $s c 06196$, through introducing extra $s s p D$ copy under the control of the promoter of carrimycin biosynthetic genes. The more concentration of SspD at appropriate time means the more the precursors degraded from of TAG for carrimycin biosynthesis. Furthermore, investigation and manipulation of the positive regulator is another effective way to enhance the yield of carrimycin.

\section{Results}

\section{The analysis of SspD, homolog of SC06196, in streptomyces spiramyceticus 54IA}

SC06196 is AMP-binding domain-containing protein to activate fatty acids by binding to coenzyme A in the Streptomyces coelicolor A3 (2). It can channel carbon flux from both intracellular TAGs and extracellular substrates into polyketide biosynthesis. SspD in Streptomyces spiramyceticus 54IA (533 amino acid residues) had high sequence similarity ( $80 \%$ identity and $88 \%$ similarity) to the SC06196 from Streptomyces coelicolor A3 (2). However, its upstream and downstream genes display significantly difference with that of $s c 06196$ (Figure 1A).

In order to gain the improvement of expressing $s s p D$ to supply more precursors for carrimycin biosynthesis, the extra constructed $s s p D$ gene was driven by the Ppks or Pbsm42 promoter in the carrimycin biosynthetic gene cluster, both of which were activated during the stationary phase of the host strain. Plasmids pSET-Ppks-sspD and pSET-Pbsm42-sspD were thus constructed (Figure 1B) and used to transform 54IA strain to obtain strain 54IA::Ppks-sspD and 54IA::Pbsm42-sspD.

Table 1 Fermentation titer of the wild-type strain and transformants

\begin{tabular}{|c|c|c|}
\hline Strains & Fermentation titer囚 $\mu \mathrm{g} / \mathrm{mL} \rrbracket$ & $\begin{array}{l}\text { Concentration of isovalerylspiramycins } \\
\llbracket \mu \mathrm{g} / \mathrm{mL} \square\end{array}$ \\
\hline 54IA & $115 \pm 13.96$ & $56.17 \pm 4.31$ \\
\hline 54IA::Ppks-sspD & $253 \pm 12.75$ & $93.63 \pm 6.63$ \\
\hline 54IA::Pbsm42-sspD & $187 \pm 9.42$ & $79.74 \pm 3.96$ \\
\hline 54IA::kasOp*-bsm42 & $964 \pm 34.87$ & $325.04 \pm 19.45$ \\
\hline 54IA::kasOp*-bsm23 & $276 \pm 18.55$ & $65.75 \pm 8.21$ \\
\hline
\end{tabular}


Date are means \pm SE of three independent biological replicates

54IA::Ppks-sspD and 54IA::Pbsm42-sspD showed higher titer than that of the original strain 54IA. As shown in Table 1, the titer of 54IA::Ppks-sspD and 54IA::Pbsm42-sspD reached $253 \pm 12.75 \mu \mathrm{g} / \mathrm{mL}$ and $187 \pm 9.42 \mu \mathrm{g} / \mathrm{mL}$, which are 2.2 and 1.6 times higher than that of $54 \mathrm{IA}$, respectively. In order to calculate the yield of the isovalerylspiramycins, the three main active components of carrimycin, the fermentation broth extractions of the strains were analyzed by HPLC. Based on the standard curves of carrimycin, the isovalerylspiramycins yield of in strain $54 \mathrm{IA}:: P p k s-s s p D(93.63 \pm 6.63 \mu \mathrm{g} / \mathrm{mL})$ and $54 \mathrm{IA}:: P b s m 42-s s p D$ $(79.74 \mu \mathrm{g} / \mathrm{mL})$ (Table 1) were significantly increased than that of $54 \mathrm{IA}(56.17 \pm 4.31 \mu \mathrm{g} / \mathrm{mL})$. The results suggest that improved $s s p D$ expression at suitable time controlled by the appropriate promoter could effectively enhance the yield of carrimycin in 54IA strain.

\section{Enhancement of carrimycin production by overexpression of Bsm23 and Bsm42 positive transcription regulators}

It has been reported that Bsm23 and Bsm42 are two positive regulators of the spiramycin biosynthesis. To investigate the performance of Bsm23 and Bsm42 in the regulation of carrimycin biosynthesis, bsm23 and bsm42were both overexpressed in 54IA strain. Plasmid pSET-kasOp*-bsm23 containing bsm23 assembled with kasOp* promoter was constructed, and plasmid pSET-kasOp*-bsm42 contained bsm42 which was also driven by kasOp* promoter (Figure 1B). The two recombinant plasmids were then transferred into 54IA to give strain 54IA:: kasOp*-bsm23 and 54IA:: kasOp*-bsm42.

In Table 1, the results showed that the titer of strain 54IA::kasOp*-bsm42 reached as high as $964 \pm 34.87$ $\mu \mathrm{g} / \mathrm{mL}$, which was 7.4 times higher than that of the original strain 54IA. Meanwhile, its isovalerylspiramycins yield could improve to $325.04 \pm 19.45 \mu \mathrm{g} / \mathrm{mL}$, about 5.8 fold higher than that of 54IA. In contrast, the fermentation titer of strain 54IA::kasOp*-bsm23 was moderately improved 2.4 times than that of 54IA, but the isovalerylspiramycins production was similar with that of 54IA. Therefore, Bsm42 was the pathway-specific positive activator for carrimycin biosynthesis. So, the improved expression level of bsm 42 could play as an indicator for high production of carrimycin in 54IA strain.

\section{Double reporter plasmids for efficient screening for carrimycin high-yield strain}

Similar to other pathway-specific positive activator, the promoter region of bsm 42 could play a direct target for variety of regulatory proteins. We attempt to adjust the expression of $b s m 42$ through mutagenesis method combining with a reporter system to serve as a screening indicator. By protoplast transformation methods, the reporter plasmids pDR-42F1R and pDR-42F2R were transduced into 54IA to obtain the F1R and F2R transformants, respectively. It was found that the wild type strain 54IA could normally grow below $2 \mu \mathrm{g} / \mathrm{mL}$ of kanamycin $(\mathrm{Km})$, however the F1R and F2R could maximally tolerate $\mathrm{Km}$ at $60 \mu \mathrm{g} / \mathrm{mL}$. About $1 \times 10^{5}$ spores of F1R and F2R were separately treated with UV and plasma, followed by spreading spores on greater than or equal to $60 \mu \mathrm{g} / \mathrm{mL}$ of $\mathrm{Km}$. The hundreds of mutants grew out for 7 days of incubation, and then the selection plates were sprayed with catechol. 608 yellowcolored mutants were randomly picked for carrimycin titer measurement. The 286 mutants (47\%) 
produced statistically higher carrimycin yield than the starting strain 54IA containing the pDR2 plasmid (Figure 2 and Table 2). The titers of positive F1R transformants (Figure 2A) were much lower than that of the selected F2R tranformants. Among F2R tranformants tested in Figure 2B, F2R-15 strain with the 200 $\mu \mathrm{g} / \mathrm{mL}$ of $\mathrm{Km}$ resistance had the highest titer, reaching at a concentration of $1010 \pm 30 \mu \mathrm{g} / \mathrm{mL}$.

Table 2 Positive rates of different F1R and F2R mutant pools

\begin{tabular}{|lll|}
\hline Mutant $(\mathrm{Km} \mu \mathrm{g} / \mathrm{mL})$ & The number of positive strain/total & Positive rate \\
\hline F1R $(60)$ & $71 / 147$ & $48 \%$ \\
\hline F2R $(90)$ & $99 / 111$ & $89 \%$ \\
\hline F2R (150) & $87 / 174$ & $50 \%$ \\
\hline F2R (200) & $18 / 89$ & $20 \%$ \\
\hline F2R (300) & $11 / 87$ & $13 \%$ \\
\hline Total & $286 / 608$ & $47 \%$ \\
\hline
\end{tabular}

As shown in Figure 2C, only a few of F1R mutant colonies (Figure. 2C-a) was visually observable yellow color appeared on the lawns, but most of F2R mutant colonies (Figure 2C-b) displayed the significant yellow color. The XylE activities were tested in the highest yield mutants of F1R-4 and F2R-15 (Fig. 2C-C). When sprayed with substrate catechol, the colonies of F2R-15 displayed bright yellow color, at the same time the colonies of F1R-4 showed weak yellow color, while there was no visible yellow color appeared on the lawns of the starting strain 54I-A.

\section{Differentially expressed genes between the high-yield strain F2R-15 and 54IA}

Comparative analysis of transcriptome profiles from RNA-seq of the F2R-15 mutant and 54IA strains found 44 genes with obvious differences in expression, including 20 significantly up-regulated and 24 down-regulated genes (Table 3). The up-regulated genes are associated with carrimycin biosynthetic precursor, macrolide-inactivation, antibiotics transporter, oxidative phosphorylation, two sigma factors and three regulators. The improved genes of ID-6064 and ID-203 are related to the generation of acyl-CoA and Isovaleryl-CoA, which are the important building blocks of carrimycin biosynthesis. Gene of ID-803, macrolide-inactivating glycosyltransferase gene, could play an important role in self-protection to macrolide antibiotic inhibition. There are 7 enhanced expression genes involved in transporter system, especially the response to antibiotic. In addition, some increased genes referring to oxidative phosphorylation might provide more energy for the secondary metabolism. The improvement of sigma factors and three regulatory genes may be directly or indirectly involved in regulating the biosynthesis of carrimycin. The most of down-regulated genes were attributed to 10 secondary metabolites gene clusters referring to the biosynthesis of siderphore, terpene, lassopeptide, feglymycin, ectoine and some $t 1 p k s-$ 
nrps compounds. Strangely, the deoxysugar biosynthetic genes of carrimycin in F2R-15 mutant also showed lower expression level than that in 54IA. As for genes in synthesis and metabolism of biomacromolecules, some important genes involved in metabolism of amino acids and nucleotides were increased, however, the key biosynthetic genes of the two primary metabolites were decreased. These results are consistent with the general knowledge that the secondary metabolism initiation would inhibit the primary metabolism.

Table 3 Differentially expressed genes between the F2R-15 mutant and 54IA 


\begin{tabular}{lll}
\hline ID Gene description & Regulation & $\begin{array}{l}\text { Fold } \\
\text { change }\end{array}$
\end{tabular}

Precursor biosynthesis

\begin{tabular}{|c|c|c|c|c|}
\hline 6064 & $\begin{array}{l}\text { pyruvate dehydrogenase E1 } \\
\text { component subunit alpha }\end{array}$ & UP & 6.34 & $\begin{array}{l}\text { Glycolysis, acyl-CoA } \\
\text { biosynthesis }\end{array}$ \\
\hline 203 & DNA alkylation response protein, & UP & 2.22 & $\begin{array}{l}\text { Isovaleryl-CoA dehydrogenase } \\
\text { activity, the leucine degradation } \\
\text { pathway }\end{array}$ \\
\hline
\end{tabular}

Macrolide-inactivating

$803 \begin{aligned} & \text { macrolide-inactivating } \\ & \text { glycosyltransferase }\end{aligned} \quad$ UP $3.68 \quad \begin{aligned} & \text { Response to macrolide } \\ & \text { antibiotic }\end{aligned}$

Transporter

\begin{tabular}{|c|c|c|c|c|}
\hline 2176 & $A B C$ transporter permease & UP & 5.17 & $\begin{array}{l}\text { Efflux transmembrane } \\
\text { transporter activity }\end{array}$ \\
\hline 5715 & Esterase & UP & 4.49 & $\begin{array}{l}\text { ATPase activity, glycine betaine } \\
\text { transport }\end{array}$ \\
\hline 711 & ATP-binding protein DrrA & UP & 4.43 & $\begin{array}{l}\text { Daunorubicin resistance } A B C \\
\text { transporter }\end{array}$ \\
\hline 696 & ABC-F family protein & UP & 3.76 & $\begin{array}{l}\text { ATPase activity, response to } \\
\text { antibiotic }\end{array}$ \\
\hline 518 & MFS transporter & UP & 2.91 & Sporulation \\
\hline 1243 & $\begin{array}{l}\text { Efflux RND transporter permease } \\
\text { subunit }\end{array}$ & UP & 2.58 & $\begin{array}{l}\text { Transmembrane transporter } \\
\text { activity, response to antibiotic }\end{array}$ \\
\hline 6822 & ABC transporter, srmB(bsm25) & UP & 2.00 & $\begin{array}{l}\text { ATPase activity, response to } \\
\text { antibiotic }\end{array}$ \\
\hline
\end{tabular}

Oxidative phosphorylation

\begin{tabular}{|c|c|c|c|c|}
\hline 5654 & $\begin{array}{l}\text { NADH-quinone oxidoreductase } \\
\text { subunit L }\end{array}$ & UP & 5.64 & \multirow{4}{*}{ Oxidative phosphorylation } \\
\hline 2106 & $\begin{array}{l}\text { NADH-quinone oxidoreductase } \\
\text { subunit M }\end{array}$ & UP & 5.50 & \\
\hline 5817 & $\begin{array}{l}\text { NADH-quinone oxidoreductase } \\
\text { subunit L }\end{array}$ & UP & 4.38 & \\
\hline 84 & $\begin{array}{l}\text { NADH-quinone oxidoreductase } \\
\text { subunit G }\end{array}$ & UP & 2.80 & \\
\hline
\end{tabular}

Sigma factor

$1068 \begin{aligned} & \text { SigE family RNA polymerase } \\ & \text { sigma factor }\end{aligned} \quad$ UP $\quad 2.79 \quad \begin{aligned} & \text { DNA-binding transcription } \\ & \text { factor activity }\end{aligned}$




$699 \begin{aligned} & \text { Sigma-70 family RNA } \\ & \text { polymerase sigma factor }\end{aligned} \quad$ UP $\quad 2.55 \quad \begin{aligned} & \text { DNA-binding transcription } \\ & \text { factor activity }\end{aligned}$

Regulator

\begin{tabular}{clccl}
2796 & VWA domain-containing protein & UP & 6.11 & $\begin{array}{l}\text { ATPase activity, signal } \\
\text { transduction }\end{array}$ \\
\hline 1928 & $\begin{array}{l}\text { AfsR family transcriptional } \\
\text { regulator }\end{array}$ & UP & 4.56 & $\begin{array}{l}\text { Regulation of transcription } \\
\text { (Hyphal growth) }\end{array}$ \\
709 & $\begin{array}{l}\text { Helix-turn-helix transcriptional } \\
\text { regulato }\end{array}$ & UP & 2.05 & $\begin{array}{l}\text { Phosphorelay signal } \\
\text { transduction system }\end{array}$
\end{tabular}

Amino acid metabolism

\begin{tabular}{|lllll|}
\hline 1738 & $\begin{array}{l}\text { 4-hydroxyphenylpyruvate } \\
\text { dioxygenase }\end{array}$ & UP & 5.13 & $\begin{array}{l}\text { Tyrosine and phenylalanine } \\
\text { metabolism }\end{array}$ \\
\hline 2137 & glutamine synthetase & DOWN & 5.81 & Glutamine biosynthetic process \\
\hline 827 & $\begin{array}{l}\text { glutamate synthase large } \\
\text { subunit }\end{array}$ & DOWN & 3.48 & $\begin{array}{l}\text { Glutamate biosynthetic } \\
\text { process }\end{array}$ \\
\hline 434 & 3-isopropylmalate dehydratase & DOWN & 2.83 & $\begin{array}{l}\text { Valine, leucine and isoleucine } \\
\text { biosynthesis }\end{array}$ \\
\hline
\end{tabular}

Nucleotide metabolism

\begin{tabular}{|lllll}
357 & purine-nucleoside phosphorylase & DOWN & 6.49 & $\begin{array}{l}\text { Purine metabolism, Pyrimidine } \\
\text { metabolism }\end{array}$ \\
\hline 955 & adenosine deaminase, & DOWN & 5.00 & Nucleotide metabolic process \\
\hline
\end{tabular}

Secondary metabolites gene clusters

\begin{tabular}{|c|c|c|c|c|}
\hline 1832 & $\begin{array}{l}\text { lucA/lucC family siderophore } \\
\text { biosynthesis protein }\end{array}$ & DOWN & 8.33 & \multirow[t]{3}{*}{$\begin{array}{l}\text { Desferrioxamine B biosynthetic } \\
\text { gene cluster ( Siderophore) }\end{array}$} \\
\hline 1546 & $\begin{array}{l}A B C \text { transporter substrate- } \\
\text { binding protein }\end{array}$ & DOWN & 7.69 & \\
\hline 2436 & $\begin{array}{l}\text { aspartate aminotransferase } \\
\text { family protein }\end{array}$ & DOWN & 5.92 & \\
\hline 472 & lucA/lucC family protein & DOWN & 7.30 & $\begin{array}{l}\text { Kanamycin biosynthetic gene } \\
\text { cluster }\end{array}$ \\
\hline 730 & $\begin{array}{l}\text { iron chelate uptake } A B C \\
\text { transporter family permease } \\
\text { subunit }\end{array}$ & DOWN & 4.55 & $\begin{array}{l}\text { siderophore biosynthetic gene } \\
\text { cluster }\end{array}$ \\
\hline 1398 & serine hydroxymethyltransferase & DOWN & 3.02 & \multirow{2}{*}{$\begin{array}{l}\text { ectoine-butyrolactone } \\
\text { biosynthetic gene cluster }\end{array}$} \\
\hline 503 & $\begin{array}{l}A B C \text { transporter permease } \\
\text { subunit }\end{array}$ & DOWN & 2.75 & \\
\hline 422 & purine permease & DOWN & 3.83 & $\begin{array}{l}\text { t1pks-nrps metabolite } \\
\text { biosynthetic gene cluster }\end{array}$ \\
\hline
\end{tabular}




\begin{tabular}{|c|c|c|c|c|}
\hline 1820 & VWA domain-containing protein & DOWN & 2.56 & \\
\hline 16 & $\begin{array}{l}\text { NDP-aminohexose N- } \\
\text { dimethyltransferase (bsm22) }\end{array}$ & DOWN & 3.27 & \multirow{4}{*}{$\begin{array}{l}\text { Deoxysugar biosynthesis of } \\
\text { spiramycin }\end{array}$} \\
\hline 92 & $\begin{array}{l}\text { NDP-hexose dehydratase } \\
\text { (bsm26) }\end{array}$ & DOWN & 2.76 & \\
\hline 74 & GTPase (bsm27) & DOWN & 2.39 & \\
\hline 18 & glycosyltransferase, bsm28-35 & DOWN & 2.26 & \\
\hline 530 & $\begin{array}{l}\text { DUF350 domain-containing } \\
\text { protein }\end{array}$ & DOWN & 3.22 & \multirow[t]{2}{*}{$\begin{array}{l}\text { Terpene biosynthetic gene } \\
\text { cluster }\end{array}$} \\
\hline 1046 & $\begin{array}{l}\text { iron-containing alcohol } \\
\text { dehydrogenase family protein }\end{array}$ & DOWN & 2.04 & \\
\hline 873 & $\begin{array}{l}\text { diaminobutyrate--2-oxoglutarate } \\
\text { aminotransferase }\end{array}$ & DOWN & 2.98 & $\begin{array}{l}\text { Ectoine biosynthetic gene } \\
\text { cluster }\end{array}$ \\
\hline 87 & $\begin{array}{l}\text { peptide-N4-asparagine amidase } \\
\text { A }\end{array}$ & DOWN & 2.83 & $\begin{array}{l}\text { Feglymycin biosynthetic gene } \\
\text { cluster }\end{array}$ \\
\hline 857 & AAA family ATPase & DOWN & 2.24 & $\begin{array}{l}\text { ladderane-nrps biosynthetic } \\
\text { gene cluster }\end{array}$ \\
\hline 1704 & acetylornithine transaminase & DOWN & 2.10 & $\begin{array}{l}\text { Lassopeptide biosynthetic } \\
\text { gene cluster }\end{array}$ \\
\hline
\end{tabular}

The expressions of bsm23 (ID-60), bsm42 (ID-834) and the major up-regulated genes were further validated repeatedly by qPCR (Figure 3 ). The results showed that the expression level of these upregulated genes were essentially in agreement with that of trancriptome profiles, only gene 6064, 2176 and 2796 showed much higher expression level. However, the bsm25 (ID-6822), bsm42 (ID-834) and bsm23 (ID-60) located in carrimycin biosynthetic gene cluster had similar expression level between the F2R-15 mutant and 54IA starting strains.

\section{Discussion}

In this article, we explored the feasibility of increasing $s s p D$ expression and overexpression of positive transcriptional regulators, $b s m 23$ and $b s m 42$, for improvement of the carrimycin production in the 54IA strain. The production of carrimycin was moderately increased in the plasmids inserted strain containing the $s s p D$ gene under control of the pks or bsm42 promoters. The SspD, SC06196 homolog, was considered to involve in degradation of TAG to produce the synthetic substrates for carrimycin biosynthesis in 54IA strain. The extra $s s p D$ gene copy was designed to expression at the starting period of carrimycin biosynthesis to increase substrate supply for PKS assemble line. This strategy just moderately improved carrimycin biosynthesis probably due to insufficient Ssp improved expression on the control of the pks or bsm42 promoter in 54IA strain. 
Generally, the antibiotic production is stringently and elaborately regulated by pyramidal transcriptional regulatory cascades, including signaling pathways, global regulators, pathway-specific regulator, and feedback regulation [29]. Combination of different strategies to manipulate regulatory genes can achieve higher antibiotic production in both the native and/or heterologous host. There are many reports proved that overexpression of pathway specific positive regulators can improve the production of antibiotics, such as TyIS or (especially) TyIR for Tylosin [30], ToyA for toyocamycin biosynthesis [31], SInR modulated salinomycin biosynthesis [32], and so on. In this study, the Bsm42 plays the similar role in carrimycin biosynthesis, and its overexpression can significantly enhance the yield of carrimycin. Bsm23, however, is also a necessary regulator for carrimycin biosynthesis, but its higher expression cannot significantly enhance the antibiotics yield. The expression level of positive regulator is not always related to the production of antibiotic. These positive regulators also emerged in other antibiotics producing strain. For example, overexpression of milR with a strong constitutive promoter led to decreasing of milbemycin production in S. bingchenggensis [33]. In conclusion, the threshold of the over-expressed regulator was a key point to determine the production of antibiotic.

In view of the production of carrimycin correlated with the level of the bsm42 expression, the two different length of promoter of bsm 42 was ligated to two reporter genes acting as indicator for screening carrimycin enhanced mutants. In our previous work, a stable isovalerylspiramycin I high-producing strain yielding $2000 \mu \mathrm{g} / \mathrm{mL}$ was obtained though atmospheric and room temperature plasma mutagenesis combined ultraviolet radiation [34]. In this study, this mutagenesis method was used to treat the 54IA containing the reporter plasmids. The bsm42 promoter combined with two reporter genes is efficient selective marker for screening high production of carrimycin through $\mathrm{Km}$ resistant and color changes in mutants. The results demonstrated that the shorter promoter of the $b s m 42$ was more suitable for selection of the carrimycin high-yield strains. The efficiently selected strain F2R-15 produced carrimycin at a concentration of $1010 \pm 30 \mu \mathrm{g} / \mathrm{mL}$, which was about 9 times higher than that of the original strain 54IA. The F2R-15 was selected from the plate of $\mathrm{Km}$ at $200 \mu \mathrm{g} / \mathrm{mL}$, but not from the higher resistant concentration of $\mathrm{Km}$. These results suggested the continuous high expression of bsm42 was not always benefit for carrimycin biosynthesis.

The up-regulated genes in transciptome profiles of F2R-15 strain and 54IA were related to the macrolide resistant, transport, biosynthetic precursors from TCA or amino acid catabolism. The feedback regulation is often brought by antibiotic to coordinate antibiotic production and transport. Evidences have shown that antibiotic, as ligand for proper regulator, affects the final production in Streptomyces. The expression of antibiotic biosynthetic genes was modulated by the RedZ and undecylprodigiosin complex [35]. The activity of AtrA, which regulates primary and secondary metabolism, is reduced by lidamycin of Streptomyces globisporus and actinorhodin (ACT) of S. coelicolor [36]. Export of antibiotic is important for the producer to reduce the intracellular antibiotic concentration, which can relieve self-toxicity. In Amycolatopsis mediterranei, $\triangle$ rifQ mutant brought overexpression of RifP. The accelerated export of rifamycin may reduce the intracellular rifamycin concentration, relieve other possible feedback inhibition of rifamycin biosynthesis and finally lead to more than two-fold improvement of rifamycin B production [37]. Overexpression of DrrC, which provide self-resistance to DNR and DXR, achieved 5.1-fold increase in 
DXR production in S. peucetius ATCC 27952 [38]. Transporters enhance the efflux of the self-produced antibiotics, which can be an important strategy for self-protection from self-toxicity.

The down-regulated genes were mainly located in the other secondary metabolites biosynthetic gene clusters, which might reduce competition for biosynthetic substrates and energy of carrimycin. The decreased genes involved in 10 secondary metabolites gene clusters for the biosynthesis of siderphore, terpene, lassopeptide, feglymycin, ectoine and some t1pks-nrps compounds. However, the most of carrimycin biosynthetic genes in F2R-15 were a little higher expression level than 54IA starting strain, and even the deoxysugar biosynthetic genes were decreased expression. The possible reason is the inappropriate harvesting time of the strains in which production of the carrimycin starts to decline.

The above data showed that manipulation of regulatory cascades can be an efficient way to enhance the production of antibiotic. It is obvious that the balance and synergy between primary and secondary metabolism is very important for the overproduction of antibiotic. Rewiring regulatory network combined with metabolic engineering will be a more powerful way to enhance the production of antibiotic in Streptomyces [39]. On the basis of understanding the regulation of antibiotic biosynthesis, rewiring the regulatory network is much more efficient to optimize antibiotic producers than the classical random mutagenesis methods.

\section{Material And Methods}

\section{Strains, plasmids, culture conditions and primers}

All strains and plasmids used in this study are listed in Table S1. The original strain Streptomyces spiramyceticus 54IA was generated from S. spiramyceticus 1941 by inserting ist and acyB2 genes into the downstream of the spiramycin gene cluster [8]. The slant/plate medium, seed medium, and culture conditions for $S$. spiramyceticus were prepared according to previously described methods [39]. Streptomyces strains were cultivated at $28^{\circ} \mathrm{C}$ for $120 \mathrm{~h}$ in soluble fermentation medium for isolation of total RNA. Soluble fermentation medium (per $100 \mathrm{~mL}$ ) contained: dextrin, $5.0 \mathrm{~g} ; \mathrm{NaCl}, 1 \mathrm{~g} ; \mathrm{MgSO}_{4}, 0.55 \mathrm{~g}$; $\mathrm{CaCO}_{3}, 0.5 \mathrm{~g} ; \mathrm{NH}_{4} \mathrm{NO}_{3}, 0.7 \mathrm{~g}, \mathrm{KH}_{2} \mathrm{PO}_{4}, 0.065 \mathrm{~g} ; \mathrm{ZnSO}_{4} \cdot 7 \mathrm{H}_{2} \mathrm{O} 0.01 \mathrm{~g} ; \mathrm{CoCl}_{2}, 5^{\prime} 10^{-5} \mathrm{~g}$; with pH adjusted to 7.2 before autoclaving. The primers used are listed in Table $\mathrm{S} 2$.

\section{DNA isolation, manipulation, sequencing, and bioinformatics analysis}

Routine DNA manipulation with E. coli and recombinant DNA techniques in Streptomyces species were performed as described previously [40]. Routine DNA sequencing was carried out by The Beijing Ruibiotech (Beijing, China). Primers were synthesized by Sangong (Shanghai, China). Protein secondary structure predictions were performed using the NCBI BLAST program (https://blast.ncbi.nlm.nih.gov/Blast.cgi). The multiple sequence alignments and homology comparisons were performed using Clustal W and BLAST software.

\section{Genetic manipulation}


All plasmids constructed in this study were introduced into S. spiramyceticus 54IA according to the PEGassisted protoplast transformation method reported previously [41]. To investigate the availability of sco6196 for improving carrimycin biosynthesis in S. spiramyceticus 54IA, the plasmids, pSET-Ppks-sspD and pSET-Pbsm42-sspD, were constructed to increase the expression of $s s p D$ under the control of $P p k s$ and $P b s m 42$ promoter, respectively. The $s s p D$ gene was amplified using primers $s s p D-F / s s p D-R$ from the genomic DNA of Streptomyces spiramyceticus. The Ppks and Pbsm42 promoter were amplified using primers Ppks-F/Ppks-R and Pbsm42-F/Pbsm42-R from the genomic DNA of S. spiramyceticus 54IA. The fragments containing promoter Ppks or Pbsm42 with $s s p D$ gene were inserted into the $B a m \mathrm{HI} / \mathrm{Xbal}$ sites of pSET152 to obtain the resultant plasmids $p S E T-P p k s-s s p D$ and pSET-Pbsm42-sspD.

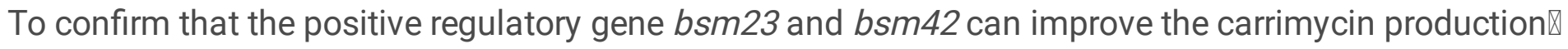
bsm 23 and bsm 42 were amplified by the primers from the genomic DNA of $S$. spiramyceticus 54IA, and then inserted into $\mathrm{Ndel} / \mathrm{Xbal}$ sites of PSET152, under the control of the constitutive promoter $k a s O p^{\star}$ to get the plasmids pSET-kasOp*-bsm23 and pSET-kasOp*-bsm42 .

\section{The construction of $x y / E$ and neo double-reporter genes controlled by promoters of bsm42}

The promoter of bsm 42 could play the indicator for enhanced carrimycin biosynthesis. The $300 \mathrm{bp}$ promoter of $b s m 42$ was amplified by the primer Pbsm42-F1 and Pbsm42-R, and the primer Pbsm42-F2 and $\mathrm{Pbsm} 42-\mathrm{R}$ for the $200 \mathrm{bp}$ length promoter of $\mathrm{bsm} 42$. The two promoter fragments were digested by Not I, then ligated into the upstream of the two reporter genes neo (kanamycin resistance gene) and $x y l E$ gene at the pDR2 vector to obtain pDR-42F1R and pDR-42F2R plasmids. The neo was used to ensure the basic selection efficiency while $x y I E$ was used to detect target over-expression and visually display the over-expression differences among mutants. The activity of XylE could be detected by spraying catechol on colonies in a selection plate or quantitatively measured in cell-free extract [28]. pDR-42F1R and pDR42F2R plasmids were individually transduced into the 54IA strain to obtain the resultant strains $S$. spiramyceticus F1R and F2R. The 54IA strain containing PDR2 was as the control strain.

\section{Streptomyces spiramyceticus F1R and F2R mutated by UV and plasma}

The lethality rates of $S$. spiramyceticus F1R and F2R in five different UV treating times were investigated. After treating for 60,75 and 90 seconds in the UV, the lethality rates of the F2R spores increase to $74.43 \%$, $79.15 \%, 95.00 \%$ respectively, and the lethality rates of the F1R spores could reach $55.48 \%, 67.77 \%$, $91.54 \%$ respectively. As a result, to obtain the desirable lethality rates the exposure time employed in this study were $75-90$ s for F1R and $60-90$ s for F2R.

\section{Quantitative analysis of carrrimycin bioproduction using Streptomyces spiramyceticus 54IA and mutants}

S. spiramyceticus 54IA and mutants were grown on agar plates for $7 \mathrm{~d}$ at $30^{\circ} \mathrm{C}$. The spores were inoculated into $50 \mathrm{~mL}$ fermentation medium in an Erlenmeyer flask $(250 \mathrm{~mL})$ and incubated at $28^{\circ} \mathrm{C}$ and $200 \mathrm{rpm}$ for 7 days. To obtain statistically significant results, three independent strains were selected and fermentations were repeated at least three times independently. The resulting fermentation broth was 
extracted with ethyl acetate $(100 \mathrm{~mL})$, and the solvent was removed in vacuum. The extracts were dissolved in $1 \mathrm{~mL} \mathrm{CH} \mathrm{CH}_{3} \mathrm{OH}$ and centrifuged at $13,000 \mathrm{~g}$ for $10 \mathrm{~min}$, and $10 \mu \mathrm{L}$ of supernatant was subjected to HPLC analysis following the previously described system [15]. In order to calculate the yields of carrimycin in the mutants and the starting strain 54IA, a quantitative curve was established based on the relationship of integral area and the weight of carrimycin. To quantitatively analyze carrimycin titers in the plasmids transduced strains and that of the original strain, extracts of the mutant strains were diluted 10 times and then subjected to HPLC alongside analogously prepared WT-derived extract. The titers of carrimycin in different strains were calculated based on the established standard carrimycin curve. The ttest was used in the quantitative calculation of carrimycin titers in different strains.

\section{Transcriptome analysis and quantitative real-time PCR of streptomyces spiramyceticus 54IA-2 and mutant strains}

S. spiramyceticus 54IA and F2R-15 incubated for $120 \mathrm{~h}$ in soluble fermentation medium were harvested and flash-frozen in liquid $\mathrm{N}_{2}$. Frozen mycelia pellets were ground into a fine powder by using a pestle and a mortar, and total RNA was extracted using an RNAprep pure Micro Kit (TIANGEN) according to the manufacturer's instructions. Contaminating chromosomal DNA in the RNA samples was eliminated by treating with DNase I (Promega). The quantity and quality of RNA samples were assessed by measuring

the $A_{260}$ and $A_{280}$ of the samples using Nanodrop (DeNovix), and the integrity of the purified RNA samples was determined by denaturing agarose gel electrophoresis. The transcriptome analysis was performed by OE Biotech (Shanghai, People's Republic China). $P$ value $<0.05$ and foldChange $>2$ set as the threshold for significantly differential expression. Genes with more than 2-fold change and $P$ value $<0.05$ were defined as significantly regulated genes.

Quantitative real-time PCR was performed on a Light Cycler 96 (Roche) with FastStart Essential DNA Green Master (Roche). All qPCR gene-specific primers were designed to produce $\sim 150$ bp long amplicons and all reactions were performed in triplicate for three different samples using gene specific primers (Table S3). The 16S RNA gene from S. spiramyceticus 54IA was used as the internal control to normalize samples. PCR program: $96^{\circ} \mathrm{C} 1 \mathrm{~min}\left(96^{\circ} \mathrm{C} 30 \mathrm{~s}, 61^{\circ} \mathrm{C} 30 \mathrm{~s}, 72^{\circ} \mathrm{C} 1 \mathrm{~min}\right) 40 \mathrm{cycles}, 72{ }^{\circ} \mathrm{C} 10 \mathrm{~min}$. Meltingcurve analysis was performed to check the specificity of PCR amplification. Melting-curve analysis was performed to check the specificity of PCR amplification. Cycle threshold (Ct) values were obtained from the exponential phase of PCR amplification and genes expression was normalized against the genes expression of 16S RNA to generate a $\Delta \mathrm{Ct}$ value (Ct of target gene- $\mathrm{Ct}$ of endogenous control). The change in the genes' expression was calculated using $2^{-\Delta \Delta C t}$ method.

\section{Statistics}

Each experiment was replicated three times, with the error bars showing the standard deviations (SDs). To compare the difference between the test and control data, $P$ values were calculated by Student's $t$ test $(P<0.001)$. 
The fragment of sco6196 cloned from streptomyces spiramyceticus 54IA has been deposited in GenBank with the Accession OL616099.

\section{Declarations}

\section{Acknowledgements}

The authors acknowledge Prof. Weishan Wang for providing pDR2 plasmid.

\section{Availability of data and materials}

Not applicable.

\section{Funding}

CAMS Innovation Fund for Medical Sciences (2021-1-I2M-028), the National Natural Science Foundation of China (No. 82073900, 81773617), Opening Foundation of State Key Laboratory of Bioactive Substance and Function of Natural Medicines (GTZK202103).

\section{Authors' Contributions}

WQH and TYH conceived the work and drafted the manuscript. KML and JLD, equally to this study, performed experiments and analyzed data. JJL participated in the experiment and collected the data. TYH and WQH wrote and revised the manuscript. All authors read and approved the final manuscript.

\section{Correspondent authors}

Correspondence to Tianyi Hao or Weiqing He.

\section{Ethics approval and consent to participate}

Not applicable

\section{Consent for publication}

Not applicable.

\section{Competing interest}

The authors declare that they have no competing interest.

\section{References}

1. Shang G, Dai J, Wang Y. Construction and physiological studies on a stable bioengineered strain of shengjimycin. J Antibiot (Tokyo). 2001;54:66-73. 
2. Epp JK, Huber ML, Turner JR, Goodson T, Schoner BE. Production of a hybrid macrolide antibiotic in Streptomyces ambofaciens and Streptomyces lividans by introduction of a cloned carbomycin biosynthetic gene from Streptomyces thermotolerans. Gene. 1989;85(2):293-301.

3. Sun CH, Jiang W, Huang J, Jin WZ, Wang YG. Shengjimycins: a group of hybrid antibiotics, 4"acylspiramycins. Actinomycetologica. 1999;13(2):120-125.

4. Shi XG, Sun YM, Zhang YF, Zhong DF. Tissue distribution of bitespiramycin and spiramycin in rats. Acta Pharmacol Sin. 2004;25(11):1396-401.

5. Shi XG, Fawcett JP, Chen XY, Zhong DF. Structural identification of bitespiramycin metabolites in rat: A single oral dose study. Xenobiotica. 2005;35 (4): 343-358.

6. Yan H, Sun J, Wang K, Wang H, Wu S, Bao L, He W, Wang D, Zhu A, Zhang T, Gao R, Dong B, Li J, Yang L, Zhong M, Lv Q, Qin F, Zhuang Z, Huang X, Yang X, Li Y, Che Y, Jiang J.Repurposing CFDAapproved drug carrimycin as an antiviral agent against human coronaviruses, including the currently pandemic SARS-CoV-2. Acta Pharm Sin B. 2021;11(9):2850-2858.

7. Wang YG, Dai JL, Shang GD. Genetically engineered bacterial strain spiramycin streptomycetespiramyceticus WSJ-195 of bitespiramycin: CN, 02148771.5. 2004-10-06 (in Chinese).

8. Liu J, Zhang Y, He W. Construction of a novel carrimycin-producing strain by using CRISPR-Cas9 and ribosome engineering techniques. Chin J Biotechnol. 2021; 37(6):2116-2126.

9. Wang HY, Zhou HX, Dai JL, et al. Studies on space-flight breeding of genetically engineered strain of biotechmycin. Chin J Pharm Biotechnol. 2007;14(1):10-13 (in Chinese).

10. Dai JL, Li RF, Wu LZ, et al. Improvement of new generation of bitespiramycin producing strain by microwave radiation. Chin J Antibiot. 2009;34(7): 406-410, 428 (in Chinese).

11. Dai JL, Li RF, WANG YG, WU LZ, He WQ. Optimization of fermentation medium for bitespiramycin production by response surface methodology. Journal of Shenyang Pharmaceutical University. 2010;27(6):482-488 (in Chinese).

12. Li Z, Wang Y, Chu J, Zhuang Y, Zhang S. Leucine improves the component of isovalerylspiramycins for the production of bitespiramycin. Bioprocess Biosyst Eng. 2009;32:641-647.

13. Gao X, Wang Y, Chu J. A preliminary study on the impact of exogenous A-Factor analogue 1,4butyrolactone on stimulating bitespiramycin biosynthesis. Bioprocess Biosyst Eng. 2019, 42(12):1903-1913.

14. Dai JL, Wang YH, Liu YW, Xiao CY, Tong ZM, Chu J, Zhang SL, Lv GY, Wang YG. Study on the fermentation of genetically engineered strain of biotechmycin in fermentor. Chin J Antibiot. 2005;30(6):324-327, 428 (in Chinese).

15. Lu Z, Zhang X, Dai J, Wang Y, He W. Engineering of leucine-responsive regulatory protein improves spiramycin and bitespiramycin biosynthesis. Microb Cell Fact. 2019;18(1):38.

16. Dai JL, Zhang XT, Lu ZL, et al. Breeding of high isomycin-l-producing strain by MPMS composite mutagenesis with plasma and UV. Chin J Antibiot. 2018;43(2):182-188 (in Chinese). 
17. Xia H, Zhan X, Mao XM, Li YQ. The regulatory cascades of antibiotic production in Streptomyces. World J Microbiol Biotechnol. 2020;36(1):13.

18. Li L, Wei K, Liu X, Wu Y, Zheng G, Chen S, Jiang W, Lu Y. aMSGE: advanced multiplex site-specific genome engineering withorthogonal modular recombinases in Actinomycetes. Metab Eng. 2019;52:153-167.

19. Yu Z, Lv H, Wu Y, Wei T, Yang S, Ju D, Chen S. Enhancement of FK520 production in Streptomyces hygroscopicus by combining traditional mutagenesis with metabolic engineering. Appl Microbiol Biotechnol. 2019;103 (23-24):9593-9606.

20. Xia M, Huang D, Li S, Wen J, Jia X, Chen Y. Enhanced FK506 production in Streptomyces tsukubaensis by rational feeding strategies based on comparative metabolic profiling analysis. Biotechnol Bioeng. 2013;110(10):2717-2730.

21. Wang J, Liu H, Huang D, Jin L, Wang C, Wen J. Comparative proteomic and metabolomic analysis of Streptomyces tsukubaensis reveals the metabolic mechanism of FK506 overproduction by feeding soybean oil. Appl Microbiol Biotechnol. 2017;101(6):2447-2465.

22. JungWS, Yoo YJ, Park JW, Park SR, Han AR, Ban YH, Kim EJ, Kim E, Yoon YJ. A combined approach of classical mutagenesis and rational metabolic engineering improves rapamycin biosynthesis and provides insights into methylmalonyl-CoA precursor supply pathway in Streptomyces hygroscopicus ATCC 29253. Appl Microbiol Biotechnol. 2011;91(5):1389-1397.

23. Karray F, Darbon E, Oestreicher N, Dominguez H, Tuphile K, Gagnat J, Blondelet-Rouault MH, Gerbaud C, Pernodet JL, Organization of the biosynthetic gene cluster for the macrolide antibiotic spiramycin in Streptomyces ambofaciens. Microbiology. 2007;153:4111-4122.

24. Wang W, Li S, Li Z, Zhang J, Fan K, Tan G, Ai G, Lam SM, Shui G, Yang Z, Lu H, Jin P, Li Y, Chen X, Xia X, Liu X, Dannelly HK, Yang C, Yang Y, Zhang S, Alterovitz G, Xiang W, Zhang L. Harnessing the intracellular triacylglycerols for titer improvement of polyketides in Streptomyces. Nat Biotechnol. 2020;38(1):76-83.

25. Alvarez HM, Steinbuchel A. Triacylglycerols in prokaryotic microorganisms. Appl Microbiol Biotechnol. 2002;60:367-376.

26. Karray F, Darbon E, Nguyen HC, Gagnat J, Pernodet JL. Regulation of the biosynthesis of the macrolide antibiotic spiramycin in Streptomyces ambofaciens. J Bacteriol. 2010;192:5813-5821.

27. Dai J, Wang Y, Liu J, He W. The regulatory genes involved in spiramycin and bitespiramycin biosynthesis. Microbiol Res. 2020;240:126532.

28. Xiang SH, Li J, Hua Yin, Zheng JT, Yang X, Wang HB, Luo JL, Bai H, Yang KQ. Application of a doublereporter-guided mutant selection method to improve clavulanic acid production in Streptomyces clavuligerus. Metab Eng. 2009;11(4-5):310-318.

29. Xia H, Li X, Li Z, Zhan X, Mao X, Li Y. The Application of Regulatory Cascades in Streptomyces: Yield Enhancement and Metabolite Mining. Front Microbiol. 2020;11:406.

30. Cundliffe E. Control of tylosin biosynthesis in Streptomyces fradiae. J Microbiol Biotechnol. 2008;18(9):1485-1491. 
31. Xu J, Song Z, Xu X, Ma Z, Bechthold A, Yu X. ToyA, a positive pathway-specific regulator for toyocamycin biosynthesis in Streptomyces diastatochromogenes Appl Microbiol Biotechnol. 2019;103(17):7071-7084.

32. Zhu Z, Li H, Yu P, Guo Y, Luo S, Chen Z, Mao X, Guan W, Li Y. SInR is a positive pathway-specific regulator for salinomycin biosynthesis in Streptomyces albus. Appl Microbiol Biotechnol. 2017;101(4):1547-1557.

33. Zhang $\mathrm{Y}, \mathrm{He} \mathrm{H}$, Liu H, Wang H, Wang X, Xiang W. Characterization of a pathway-specific activator of milbemycin biosynthesis and improved milbemycin production by its overexpression in Streptomyces bingchenggensis. Microb Cell Fact. 2016;15(1):152.

34. Dai JL, Zhang XT, Lu ZL, et al. Breeding of high isomycin-l-producing strain by MPMS composite mutagenesis with plasma and UV. Chin J Antibiot. 2018;43 (2):182-188 (in Chinese)

35. Wang L, Tian X, Wang J, Yang H, Fan K, Xu G, Yang K, Tan H. Autoregulation of antibiotic biosynthesis by binding of the end product to an atypical response regulator. Proc Natl Acad Sci U S A. 2009;106(21):8617-8622.

36. Li X, Yu T, He Q, McDowall KJ, Jiang B, Jiang Z, Wu L, Li G, Li Q, Wang S, Shi Y, Wang L, Hong B. Binding of a biosynthetic intermediate to AtrA modulates the production of lidamycin by Streptomyces globisporus. Mol Microbiol. 2015;96(6):1257-1271.

37. Lei C, Wang J, Liu Y, Liu X, Zhao G, Wang J. A feedback regulatory model for RifQ-mediated repression of rifamycin export in Amycolatopsis mediterranei. Microb Cell Fact. 2018;17(1):14.

38. Malla S, Niraula NP, Liou K, Sohng JK. Self-resistance mechanism in Streptomyces peucetius: overexpression of $d r r A, d r r B$ and $d r r C$ for doxorubicin enhancement. Microbiol Res. 2010;165(4):259267.

39. Xia H, Zhan X, Mao XM, Li YQ. The regulatory cascades of antibiotic production in Streptomyces. World J Microbiol Biotechnol. 2020;36(1):13.

40. Kieser T, Bibb MJ, Butter MJ, Chater KF, Hopwood DA (2000) Practical Streptomyces genetics: a laboratory manual. The John Innes Foundation, Norwich.

41. Wang YG, Jin LF, Jin WZ, Zhang XH, Zeng Y, Xu XM, Jun Y. Cloning and expression of midecamycin 4"-acylase gene in spiramycin producing strain. Chin J Biotechnol. 1992;8:1-14.

\section{Figures}


A

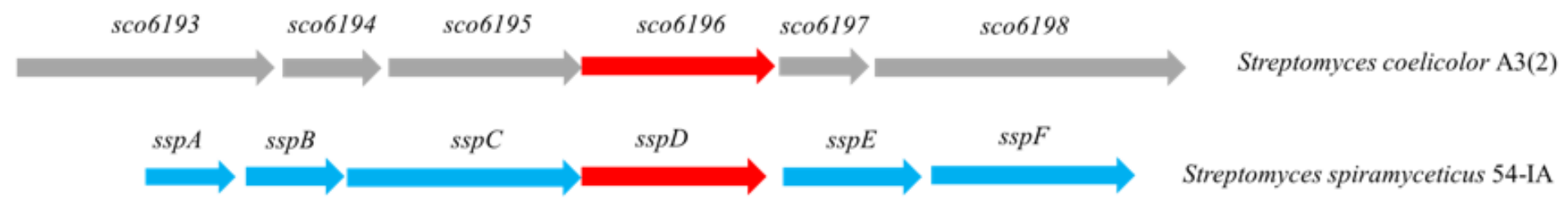

B

Spiramycin biosynthetic gene cluster $(90 \mathrm{~kb})$

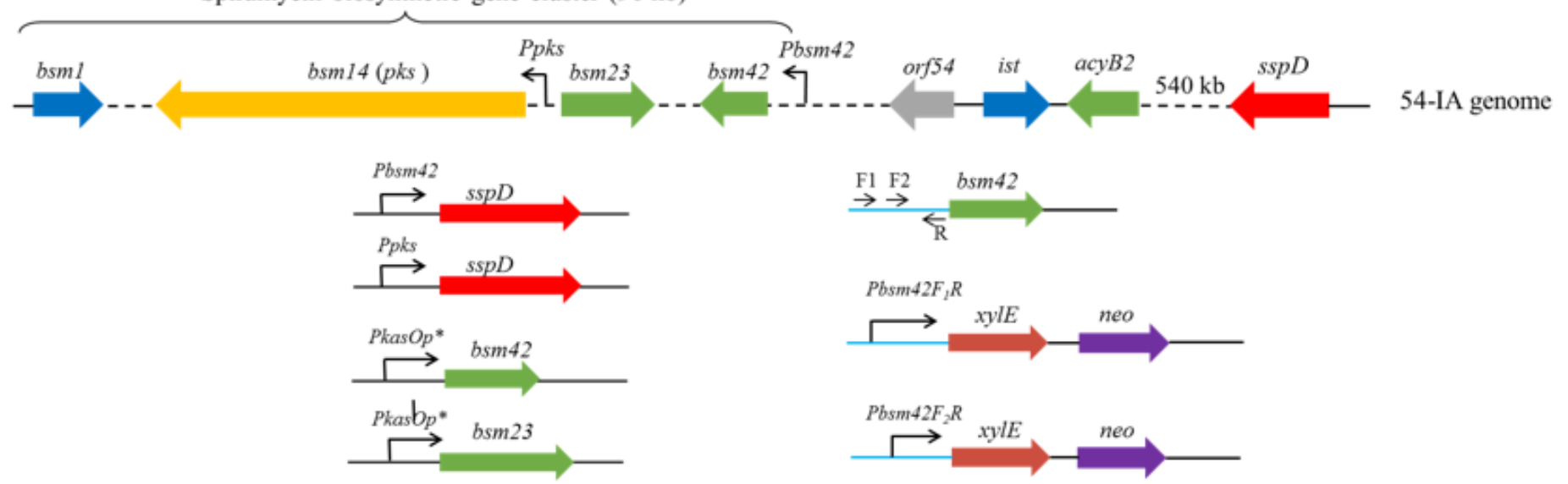

\section{Figure 1}

Bioinformatics analysis of $s s p D$ gene and construction of target genes under control different promoters. A: Alignment of the sco6196 and sspD gene clusters in Streptomyces coelicolor A3(2) and Streptomyces spiramyceticus 54IA, respectively. B: Construction of target genes under control different promoters in Streptomyces spiramyceticus 54IA. The genes are indicated by various colors. The sco6196 and sspD genes are in red color and the regulatory genes in green color. Promoters of interest (Ptarget) are indicated by black arrows. 
A

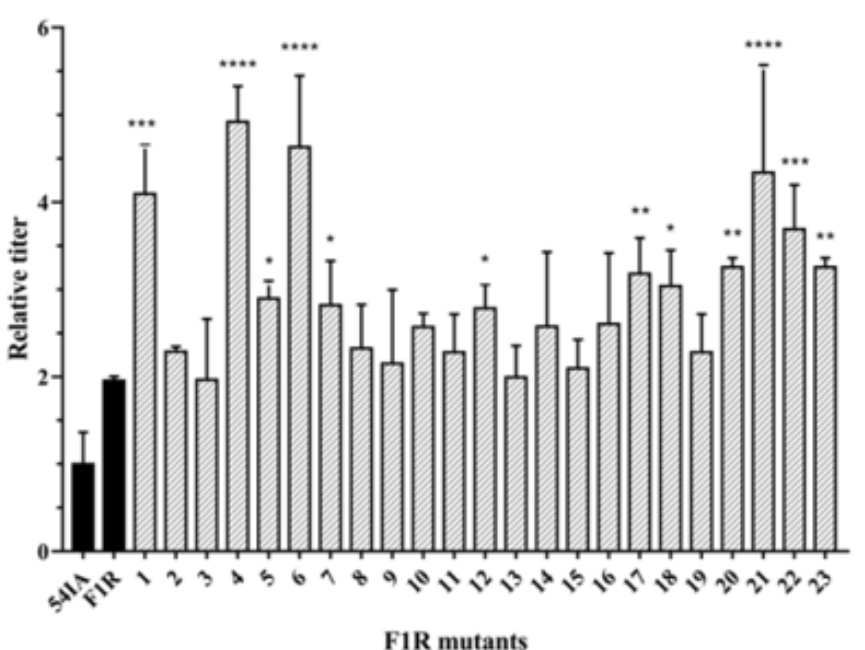

$\mathrm{C}$

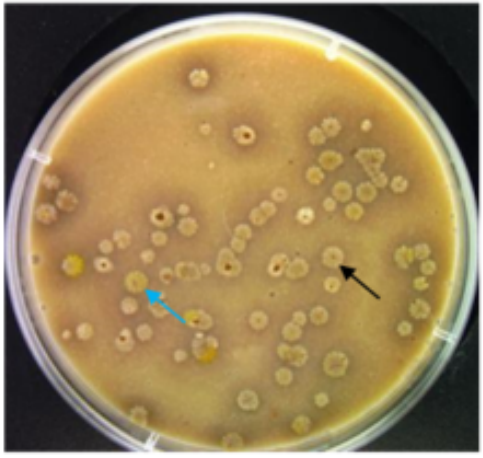

(a)

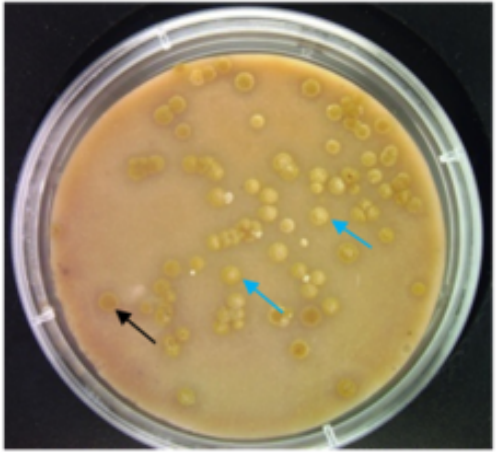

(b)

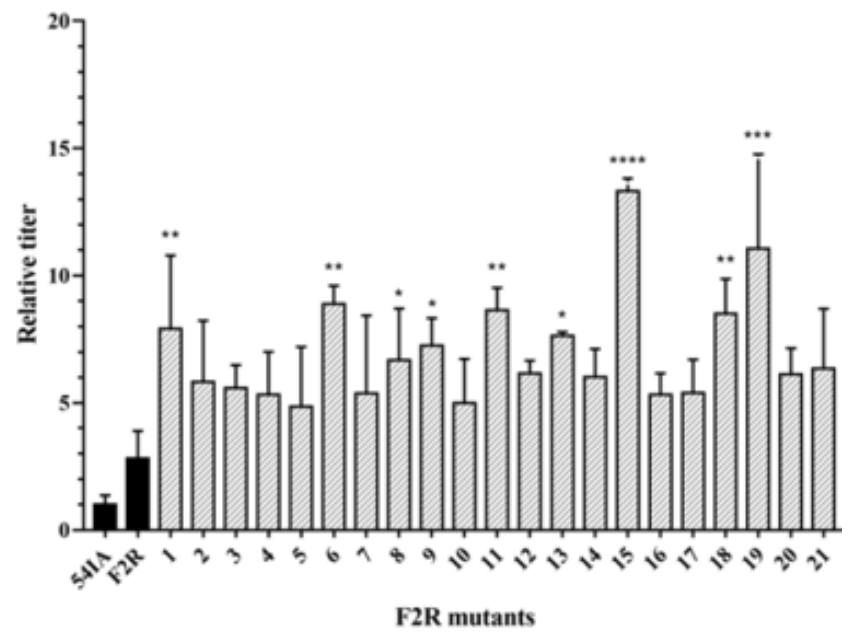

F2R mutants

$\mathrm{C}$

Figure 2

The characterization of F1R and F2R mutants. A: The titer of F1R mutants from pDR-42 F1R doublereporter system screening. 54IA: original strain S. spiramyceticus 54IA containing the pDR2 plasmid, F1R: the original pDR-42 F1R plasmid transformant, 1-23: the positive F1R mutants. B: The titer of F2R mutants from pDR-42F1R double-reporter system screening. 54IA: original strain 54IA, F1R: the original pDR-42F2R plasmid transformant, 1-21: the positive F2R mutants. The carrimycin titer is indicated as fold changes obtained by dividing mean value of each strain by the value of $S$. spiramyceticus 54IA. Error bars indicate the average standard deviations from the mean. C: F1R (a) and F2R (b) mutant colonies on selection plate sprayed with catechol. Black arrow: the typical false positive mutant, showing elevated kanamycin resistance but no observable XylE activity; blue arrow: the typical $x y / E$ over-expressing mutant (yellow). (c) Comparison of F1R-4 (left, No. 4 mutant), F2R-15 (right, No.15 mutant) and 54IA strain containing the pDR2 plasmid (under). 


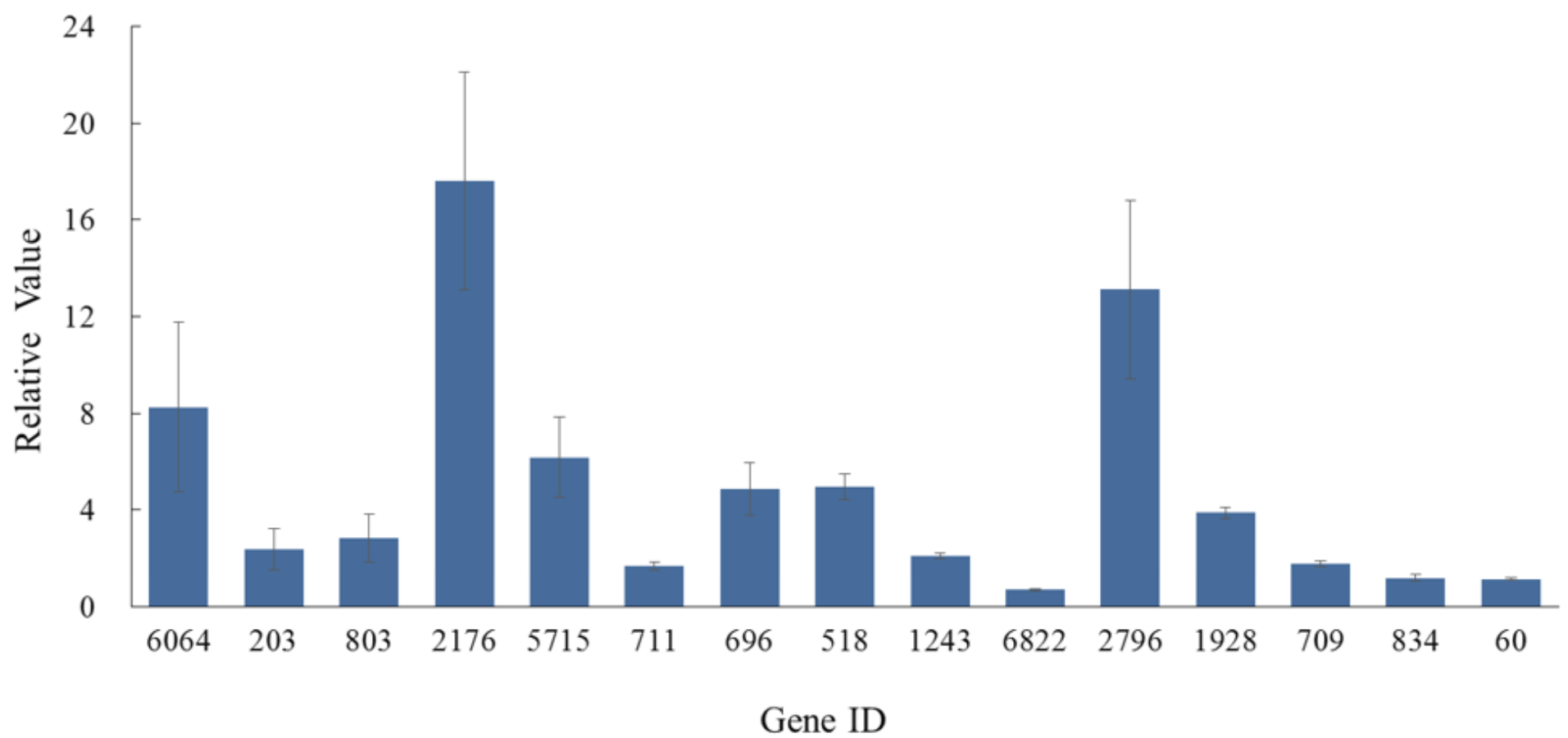

Figure 3

qPCR of some up-regulated genes in the F2R-15 mutant and 54IA starting strains $(n=3)$.

\section{Supplementary Files}

This is a list of supplementary files associated with this preprint. Click to download.

- SupplementaryTable.docx 